\title{
Sea-spray geoengineering in the HadGEM2-ES earth-system model: radiative impact and climate response
}

\author{
A. Jones ${ }^{1}$ and J. M. Haywood ${ }^{1,2}$ \\ ${ }^{1}$ Met Office Hadley Centre, Exeter, UK \\ ${ }^{2}$ College of Engineering, Mathematics and Physical Sciences, University of Exeter, Exeter, UK \\ Correspondence to: A. Jones (andy.jones@metoffice.gov.uk)
}

Received: 25 June 2012 - Published in Atmos. Chem. Phys. Discuss.: 17 August 2012

Revised: 2 November 2012 - Accepted: 9 November 2012 - Published: 16 November 2012

\begin{abstract}
The radiative impact and climate effects of geoengineering using sea-spray aerosols have been investigated in the HadGEM2-ES Earth system model using a fully prognostic treatment of the sea-spray aerosols and also including their direct radiative effect. Two different emission patterns were considered, one to maximise the direct effect in clear skies, the other to maximise the indirect effects of the seaspray on low clouds; in both cases the emissions were limited to $10 \%$ of the ocean area. While the direct effect was found to be significant, the indirect effects on clouds were much more effective in reducing global mean temperature as well as having less of an impact on global mean precipitation per unit temperature reduction. The impact on the distribution of precipitation was found to be similar in character, but less in degree, to that simulated by a previous study using a much simpler treatment of this geoengineering process.
\end{abstract}

\section{Introduction}

Geoengineering (also known as climate engineering) has recently received some considerable attention owing to the lack of progress in tackling the continued anthropogenic emissions of greenhouse gases (Robock, 2008; Lenton and Vaughan, 2009). These geoengineering schemes broadly fall into two categories: carbon dioxide removal (CDR) schemes which aim to actively remove and hence reduce atmospheric concentrations of $\mathrm{CO}_{2}$, and solar solar radiation management (SRM) schemes which aim to counter global warming by reflecting an increased proportion of sunlight back to space. While many CDR schemes may be considered relatively benign as the ultimate effect on atmospheric $\mathrm{CO}_{2}$ levels is sim- ilar to enhanced mitigation through reduced $\mathrm{CO}_{2}$ emissions, the costs involved in such schemes are currently prohibitive compared with standard mitigation approaches. Additionally, because the timescales for CDR implementation and the atmospheric lifetime of $\mathrm{CO}_{2}$ are relatively long, $\mathrm{CDR}$ cannot be used to induce a rapid cooling to counterbalance (or even potentially reverse) global warming. SRM schemes can theoretically be used to induce such a rapid cooling, with two plausible approaches being the brightening of low-level marine clouds (e.g., Latham, 1990) and the injection of $\mathrm{SO}_{2}$ or other particles into the stratosphere (e.g., Crutzen, 2006).

Studies of cloud brightening as a mechanism for geoengineering include those of Latham (1990, 2002), Latham et al. (2008), Rasch et al. (2009), Jones et al. (2009, 2011) and Latham et al. (2012). These studies have concentrated on the impact of sea-spray aerosols acting as cloud condensation nuclei $(\mathrm{CCN})$ when injected into marine clouds, thereby enhancing their albedo and reducing their precipitation efficiency. However, as shown by Partanen et al. (2012), these aerosols are also likely to have a considerable direct effect on solar radiation, the possible climate impacts of which have not yet been considered. These studies generally suggest that while global mean temperature can theoretically be manipulated to counter global warming, there are inevitably some areas where significant climate changes (in terms of precipitation) still occur. For example, significant decreases in precipitation over Amazonia have been modelled by Jones et al. (2009) when the South Atlantic stratocumulus cloud sheet was artificially brightened. However, this study has some notable limitations: it did not use a prognostic treatment of sea-salt aerosols, nor were these generated in the model using injection rates relevant to specifically designed ships 
(Salter et al., 2008). Instead, regions of marine stratocumulus clouds were brightened simply by assuming an elevated cloud droplet number concentration (CDNC) of $375 \mathrm{~cm}^{-3}$. The location and extent of these brightened regions were assumed, rather than being evaluated in terms of their potential to exert a maximal radiative forcing if such geoengineering ships were deployed. Additionally, sea-spray aerosol generation, microphysics, transport, wet and dry deposition were not explicitly modelled, and the associated direct radiative effect of the aerosol could not be included. We address these deficiencies in this study.

Assuming finite resources for sea-spray geoengineering, the question arises as to where such resources might be deployed. In this study we arbitrarily assume that sufficient resources are available to conduct geoengineering operations over $10 \%$ of the ocean's surface $(\sim 7.1 \%$ of the planet's area). We investigate where sea-spray generation could be deployed if consideration is primarily given to (a) the indirect effects or (b) the direct effects of the geoengineered sea-spray. The approach used by Jones et al. (2009) is inadequate for investigating these questions as it simply prescribed CDNC in specific regions and took no account of the direct effects of sea-spray aerosols. Consequently, a full prognostic treatment of geoengineered sea-spray aerosols has been introduced.

\section{Model description}

\subsection{General}

The model used in this study is HadGEM2-ES (Collins et al., 2011), the Earth-system configuration of the Met Office Hadley Centre climate model HadGEM2 (Martin et al., 2011). HadGEM2-ES includes components to model the atmosphere, tropospheric chemistry, aerosols, the land surface and hydrology, the terrestrial carbon cycle, the ocean, seaice and ocean biogeochemistry - see Collins et al. (2011) for details.

\section{$2.2 \mathrm{CDNC}$}

The modelling of CDNC is based on Jones et al. (2001). It is calculated from the number concentration of accumulationmode sulphate, sea-salt and carbonaceous aerosols, treated as an external mixture. Sulphate and carbonaceous aerosols from combustion are modelled prognostically, sea-salt in a diagnostic manner based on local windspeed, and biogenic carbonaceous aerosols are from a climatology; see Bellouin et al. (2011) for details. Over ocean areas remote from land the main contributors to CDNC are sea-salt and sulphate, the latter deriving mainly from the oxidation of DMS (dimethyl sulphide). DMS oxidation yields both $\mathrm{SO}_{2}$ (which may be transported some distance before conversion to sulphate aerosol) and $\mathrm{SO}_{3}$ which immediately produces sulphate aerosol in both Aitken and accumulation modes. As the aerosol scheme is single-moment, any increase in aerosol mass implies a corresponding increase in particle number concentration.

\subsection{Modelling geoengineered sea-spray aerosol}

The model has been extended to include a prognostic treatment of geoengineered sea-spray aerosol. Two variables for sea-spray aerosol are included, one to represent free particles as a log-normal accumulation mode and another for aerosols dissolved in cloud droplets, following the approach of Bellouin et al. (2011). The accumulation mode has the same size and optical parameters as used for natural film-mode seasalt aerosol in HadGEM2 (median radius $0.1 \mu \mathrm{m}$, geometric standard deviation 1.9 , density $2165 \mathrm{~kg} \mathrm{~m}^{-3}$, single-scatter albedo 1.0). The aerosol is hygroscopic and may therefore act as $\mathrm{CCN}$, and the dissolved sea-spray mode allows for effective treatment of wet deposition removal processes. The emission rate follows Eq. (1) of Korhonen et al. (2010) which relates the number flux of sea-spray aerosol particles to local 10-m windspeed; this flux is injected into the middle of the lowest model layer ( $20 \mathrm{~m}$ above the surface). Other processes which affect the sea-spray aerosol (transport, interaction with clouds and radiation, wet and dry deposition) are handled in the same manner as with the other prognostic aerosol species in HadGEM2 (Bellouin et al., 2011).

\section{Location of emissions}

In order to determine the locations for sea-spray generation we evaluate the optimal $10 \%$ of the sea-surface area for the direct and first indirect (cloud albedo) effect using the following method. One-year simulations of the model were run using two calls to the radiation scheme which allowed the radiative forcing from geoengineered sea-spray to be diagnosed whilst not affecting the evolution of the model's meteorology. Sea-spray was emitted over all parts of the ocean at rates given by the expression of Korhonen et al. (2010), reduced proportionately by any sea-ice present. The horizontal advection of the sea-spray aerosol was disabled in these simulations so that the radiative forcing of the aerosol diagnosed at a given point was due only to the local conditions (wind speed, precipitation, cloud cover, insolation etc.) at that point.

Two simulations were performed, one including only the direct effect of the geoengineered sea-spray aerosol, the other including only its first indirect effect. The radiative impact of the second indirect effect on cloud precipitation efficiency cannot be determined by using a double radiation call as it does not act instantaneously. The two distributions of annual mean forcing thus obtained (which, by design, are all over ocean and are co-located point-by-point with the location of emission) were then used as input to an iterative process whereby the regions with the weakest forcing in each 
distribution were progressively eliminated until only $10 \%$ of the ocean area remained. These two distributions were then assumed to indicate the optimal areas for sea-spray emission when considering either the direct or indirect effects as being of most interest. Unsurprisingly, clear-sky regions in the tropics between about $15^{\circ} \mathrm{N} / \mathrm{S}$ were optimal for the direct effect (a distribution we denote "D-mask"), and sub-tropical stratiform cloud regions in the Pacific, Atlantic and Indian oceans for the indirect effect (denoted "I-mask"). Jones et al. (2009) found that modifications to the stratocumulus region in the South Atlantic had a deleterious effect on precipitation over South America, so a further distribution was determined (I-mask ${ }_{N S A}$ ) which did not include the South Atlantic. This pattern essentially just increased the extent of the other regions in I-mask to compensate for the lack of the South Atlantic region. All three emission patterns are shown in Fig. 1. Note that we do not claim that this is necessarily the ideal approach for determining optimal emission locations, it is simply a plausible attempt to define these areas within the model. Different approaches are taken by Rasch et al. (2009), Partanen et al. (2012) and Alterskjær et al. (2012), for example.

\section{Background CDNC distribution}

Indirect forcing depends on the relative change in $\mathrm{CDNC}$, so cleaner clouds with lower CDNC give a greater forcing per unit CDNC increase compared with more polluted clouds, all other things being equal. The background (nongeoengineered) CDNC in the model is therefore important. Fig. 2 shows a comparison of non-geoengineered CDNC from HadGEM2-ES with two different satellite retrievals, restricted to the latitude range $70^{\circ} \mathrm{N}-60^{\circ} \mathrm{S}$ following Quaas et al. (2006). The top panel uses data from the MODerate resolution Imaging Spectroradiometer (MODIS; Platnick et al., 2003; Quaas et al., 2006) for 2000-2005, while the bottom panel uses a combination of data from MODIS and the Clouds and the Earth's Radiant Energy System (CERES) instruments (Minnis et al., 2003; Quaas et al., 2009) for 20012006. The HadGEM2-ES data are a mean of 2000-2005 and come from the final years of the "Historical" simulation performed for CMIP5, the fifth phase of the Climate Model Intercomparison Project (Taylor et al., 2009), a simulation which uses historical greenhouse gas concentrations, aerosol emissions and land-use changes for the period 1850-2005. An exact comparison is not possible as the satellite retrievals are for CDNC at cloud top which was not a diagnostic available in our simulations. We therefore compare against mean CDNC from the model between $\sim 500-1500 \mathrm{~m}$, which are appropriate altitudes for stratocumulus clouds.

There are similarities and differences between all three, with probably the greatest difference between the model and the retrievals over ocean at higher latitudes (polewards of about $30^{\circ} \mathrm{N} / \mathrm{S}$ ). However, the most important areas for geo- (a)

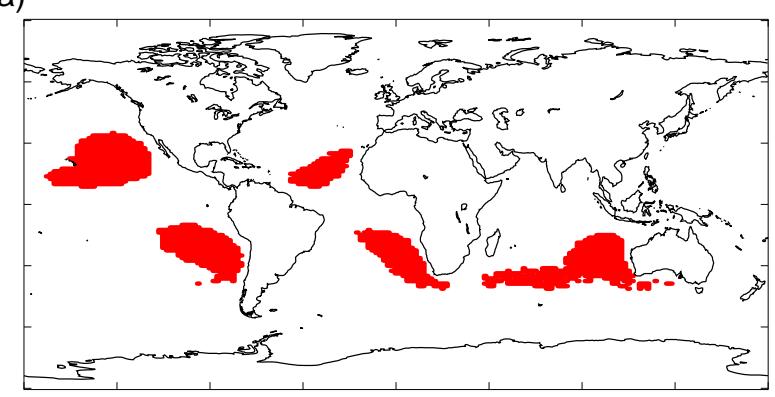

(b)

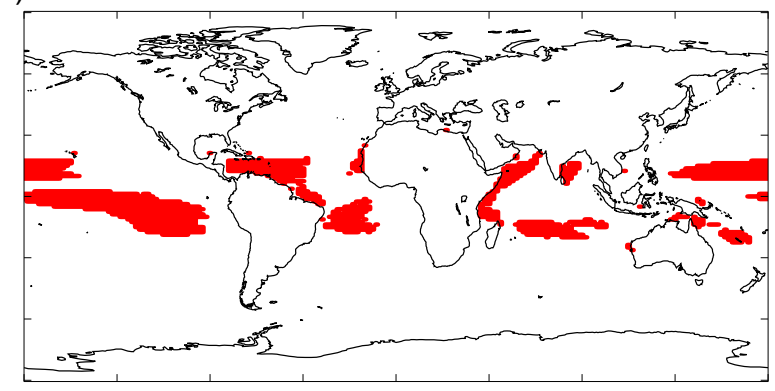

(c)

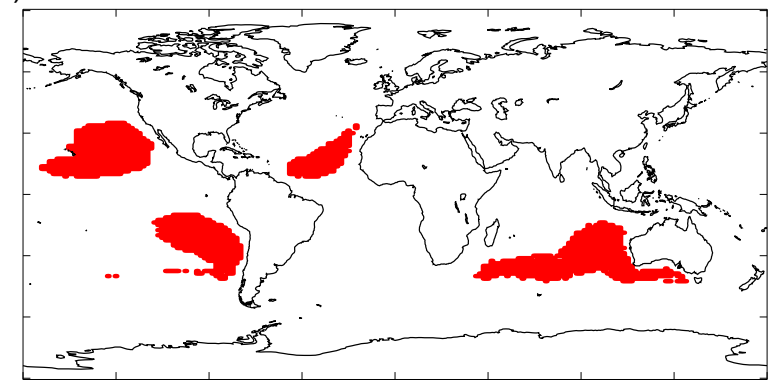

Fig. 1. The three different emission patterns used in this study: (a) I-mask; (b) D-mask; (c) I-mask ${ }_{\mathrm{NSA}}$.

engineering are generally equatorwards of these latitudes (see Fig. 1) which will reduce the impact of this difference. For ocean areas between $30^{\circ} \mathrm{N} / \mathrm{S}$ the mean model CDNC compares well with the retrievals $\left(62 \mathrm{~cm}^{-3}\right.$ compared with $59 \mathrm{~cm}^{-3}$ from MODIS and $60 \mathrm{~cm}^{-3}$ from CERES/MODIS), whereas for the ocean areas encompassed by I-mask the modelled values are lower than those retrieved $\left(41 \mathrm{~cm}^{-3}\right.$ compared with 61 and $58 \mathrm{~cm}^{-3}$ ).

\section{Forcing and radiative flux perturbation}

The absolute values of forcing produced in the idealised simulations described in Sect. 3 above are meaningless as the advection of the sea-spray aerosols is disabled. To investigate 
Table 1. Forcing $(\Delta \mathrm{F})$ and radiative flux perturbation (RFP) for geoengineered sea-spray using the three different emission patterns $\left(\mathrm{Wm}^{-2}\right)$. The forcings are from 1-year runs using two calls to the model's radiation scheme, while the RFP values are given as 10year means \pm one standard deviation. Separate forcing simulations for direct and indirect effects were not performed for the I-mask $k_{\text {NSA }}$ case.

\begin{tabular}{lccc}
\hline & D-mask & I-mask & I-mask \\
\hline$\Delta \mathrm{F}_{\text {direct }}$ & -0.45 & -0.37 & - \\
$\Delta \mathrm{F}_{1 \text { stindirect }}$ & -0.13 & -0.38 & - \\
$\Delta \mathrm{F}_{\text {total }}$ & -0.58 & -0.74 & -0.72 \\
RFP & $-0.58 \pm 0.10$ & $-1.04 \pm 0.08$ & $-0.81 \pm 0.10$ \\
\hline
\end{tabular}

the radiative forcing in a more realistic context, one-year simulations using each of the three emission patterns were performed. These simulations included both direct and first indirect effects of the sea-spray aerosol, the double radiationcall method to determine the radiative forcing of the combined direct and indirect effects was again used, and this time the sea-spray aerosol was advected as normal. The resulting annual-mean global forcings are given in Table 1 and range from $-0.74 \mathrm{Wm}^{-2}$ when using I-mask to $-0.58 \mathrm{Wm}^{-2}$ with D-mask.

Simulations were also performed to determine the individual forcings from direct and first indirect effects when using I-mask and D-mask. As the meteorology evolved identically in these four simulations, a direct comparison could be made between the resulting forcings, despite the short (1year) length of the simulations. As shown in Table 1, when using I-mask the total forcing is split almost exactly $50-50$ between the first indirect and direct effects. In contrast, when using D-mask, the majority (almost $80 \%$ ) of the combined forcing derives solely from the direct effect.

Although useful to examine the split between the direct and first indirect effects for the two emission patterns, radiative forcing does not necessarily give a good estimate of the radiative impact of aerosols as it does not take into account the second indirect effect on clouds or any other fast feedback processes (Lohmann et al., 2010). In order to estimate the radiative impact that would actually be exerted in a coupledmodel simulation, a set of experiments was performed using the atmosphere-only version of the model (which uses climatological sea-surface temperatures and sea-ice extents) to estimate the radiative flux perturbation (RFP; Haywood et al., 2009). This set consisted of four 10-year simulations: a control (no geoengineered sea-spray) and three experiments injecting sea-spray according to the I-mask, D-mask and I-mask $\mathrm{NSA}_{\text {A }}$ emission patterns. All aerosol effects are included in these runs, which evolve differently as the seaspray aerosols are allowed to interact with the meteorology. The RFP is defined as the 10-year mean difference in top-ofatmosphere net radiation between each experiment and the control. (a)

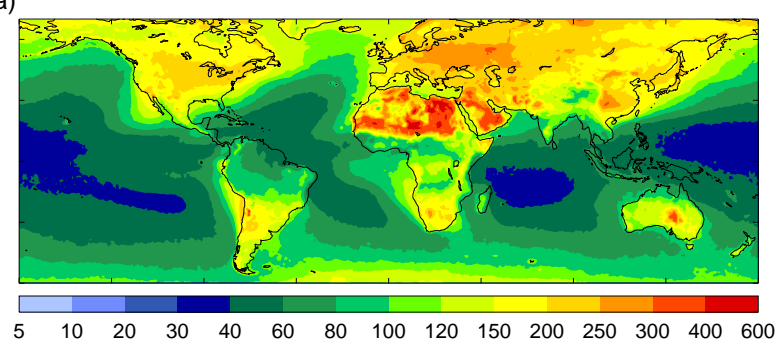

(b)

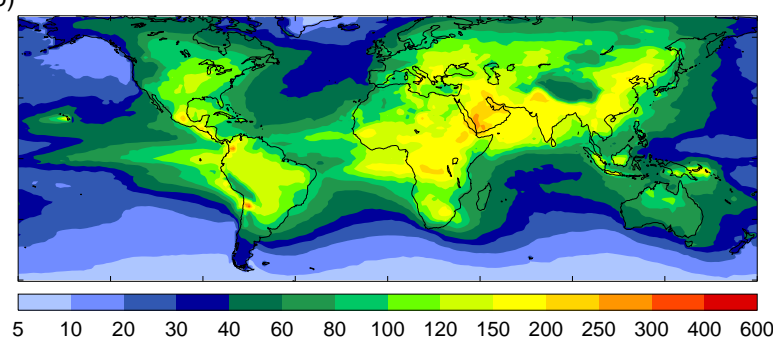

(c)

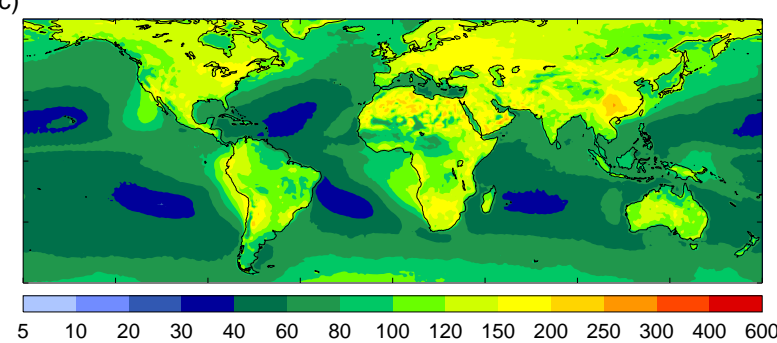

Fig. 2. (a) Annual-mean cloud-top CDNC $\left(\mathrm{cm}^{-3}\right)$ from MODIS for 2000-2005. (b) As (a) but from $\sim 500-1500 \mathrm{~m}$ altitude in HadGEM2-ES. (c) As (a) but from CERES/MODIS for 2001-2006.

As shown in Fig. 3 and Table 1, the RFP for I-mask is about $40 \%$ greater than the corresponding forcing (Table 1), most likely due to the inclusion of the second indirect effect in the RFP. In contrast, when using D-mask the resulting RFP is virtually the same as the radiative forcing, suggesting that no significant further effects are invoked when emitting in the D-mask regions. Another difference when using these emission patterns is the lifetime of the geoengineered seaspray aerosol. When using I-mask the mean lifetime is 4.8 days, increasing by over $30 \%$ to 6.3 days with D-mask. As the point of I-mask and D-mask is to target optimal areas for the indirect and direct effects, respectively, then it follows that I-mask will pick out cloudier regions with more precipitation and therefore wet deposition of aerosols than D-mask, as borne out by the differences in aerosol lifetime.

The mean RFP of $-1.04 \mathrm{Wm}^{-2}$ for I-mask may be compared with an RFP of $-0.97 \mathrm{Wm}^{-2}$ obtained by Jones et al. (2009). This earlier study modified a smaller area of cloud, confined to $3.3 \%$ of the Earth's surface, whereas here seaspray is emitted over $7.1 \%$ of the Earth's surface and is 
Table 2. RFPs $\left(\mathrm{Wm}^{-2}\right)$, global-mean changes in near-surface temperature $(\mathrm{K})$ and precipitation rate $\left(\mathrm{mm} \mathrm{day}^{-1}\right)$, the efficiency per unit RFP of the change in temperature $\left(\mathrm{K} / \mathrm{Wm}^{-2}\right)$, the change in precipitation per unit change in temperature $\left(\mathrm{mm} \mathrm{day}^{-1} / \mathrm{K}\right)$ and the change in near-surface temperature per unit emission rate of geoengineered sea-salt $\left(\mathrm{K} / \mathrm{kg} \mathrm{s}^{-1}\right)$ for the three sea-spray emission patterns and GeoMIP G4.

\begin{tabular}{lcrrrrc}
\hline & $\mathrm{RFP}$ & $\Delta T$ & $\Delta \mathrm{ppn}$ & $\frac{\Delta T}{\mathrm{RFP}}$ & $\frac{\Delta \mathrm{ppn}}{\Delta T}$ & $\frac{\Delta T}{\mathrm{SS}_{\mathrm{GE}}}$ \\
\hline D-mask & -0.58 & -0.13 & -0.014 & 0.22 & 0.113 & $-0.7 \times 10^{-4}$ \\
I-mask & -1.04 & -0.54 & -0.042 & 0.52 & 0.077 & $-3.3 \times 10^{-4}$ \\
I-mask $_{\text {NSA }}$ & -0.81 & -0.49 & -0.037 & 0.61 & 0.075 & $-3.0 \times 10^{-4}$ \\
G4 & -1.37 & -0.97 & -0.067 & 0.71 & 0.069 & - \\
\hline
\end{tabular}

allowed to spread out from the original emission area. However, Jones et al. (2009) also increased CDNC values more: for clouds at $\sim 1 \mathrm{~km}$ in the emission regions, the mean increase in Jones et al. (2009) was more than $200 \%$ compared with $\sim 32 \%$ here. Partanen et al. (2012), who also use a fully prognostic treatment of sea-spray aerosol and include its direct radiative effect, obtain an RFP of $-0.8 \mathrm{Wm}^{-2}$ when limiting sea-spray emissions to similar regions and areal extent as Jones et al. (2009).

\section{Climate impacts}

\subsection{Experiment design}

A set of HadGEM2-ES simulations were used to investigate the potential climate impacts of geoengineered seaspray. The control was the RCP4.5 simulation performed for CMIP5. This simulation starts in 2006 and then follows a scenario of changing greenhouse gas concentrations, aerosol emissions and land-use changes such that the anthropogenic forcing in the year 2100 is approximately $4.5 \mathrm{Wm}^{-2}$ compared with the preindustrial period (Moss et al., 2010). Based on this control, three simulations which included geoengineered sea-spray emissions were initialised in the year 2020 and integrated forwards for 50 years. The simulations included all modelled forcing effects of the sea-spray aerosol and differed only in which of the three emission patterns described above were used. The experimental design follows that of the Geoengineering Model Intercomparison Project (GeoMIP; Kravitz et al., 2011) and allows a comparison of the results presented here with those from the hypothetical stratospheric aerosol solar radiation management simulations of GeoMIP. We include some results from the GeoMIP G4 experiment, which involves continuously emitting $5 \mathrm{Tg}\left[\mathrm{SO}_{2}\right]$ per year into the lower stratosphere from 2020 to 2069. This yields a somewhat larger RFP $\left(-1.37 \mathrm{Wm}^{-2}\right)$ than sea-spray emissions - see Table 2.

The results presented below are generally means over the final 30 years of the geoengineering period (2040-2069 inclusive).

\subsection{Surface temperature}

The mean changes in near-surface air temperature with respect to RCP4.5 are shown in Fig. 4 and Table 2. Geoengineering using each of the three emission patterns generates global-mean cooling, but differing considerably in degree. The I-mask and I-mask ${ }_{\mathrm{NSA}}$ emission patterns induce similar global-mean changes of $-0.54 \pm 0.10 \mathrm{~K}$ and $-0.49 \pm 0.11 \mathrm{~K}$, respectively, with the greatest cooling in the sub-tropics over the ocean (i.e. broadly co-located with the emissions) and in the Arctic. The changes in the Arctic are due to the icealbedo feedback which locally enhances the response to the general global cooling caused by the sea-spray aerosols. In contrast, the temperature response when using the D-mask emission patterns is considerably less at $-0.13 \pm 0.10 \mathrm{~K}$. There is a diffuse band of cooling in the tropics where the sea-spray aerosol was emitted, but the greatest regional temperature change is again in the Arctic. There is also a noticeable warming in the Antarctic; this is due to a dynamical response in which the strength of the zonal winds at around $50-60^{\circ} \mathrm{S}$ are associated with the temperature at higher latitudes (Landrum et al., 2012). Although zonal winds in this region weaken in all three cases, the stronger cooling when using I-mask and I-mask $\mathrm{NSA}_{\mathrm{N}}$ appears to dominate, although there are still areas of significant Antarctic warming in these cases.

The evolution of global-mean near-surface air temperature for the three sea-spray experiments are shown in Fig. 5 along with that from the unmitigated RCP4.5 simulation used as a control; the results from the GeoMIP G4 simulation are also included for reference. The greater effectiveness of the I-mask and I-mask ${ }_{\text {NSA }}$ patterns is obvious, although note that the mean temperature in D-mask does differ from RCP4.5 at the $5 \%$ significance level. The cooling in G4 is noticeably greater, due in part to the rather larger RFP.

\subsection{Precipitation}

The changes in annual-mean precipitation rate when using the three different emission patterns are given in Table 2 and the distributions shown in Fig. 6a-c. Also shown (Fig. 6d) is the change in precipitation in RCP4.5 (mean 
(a)
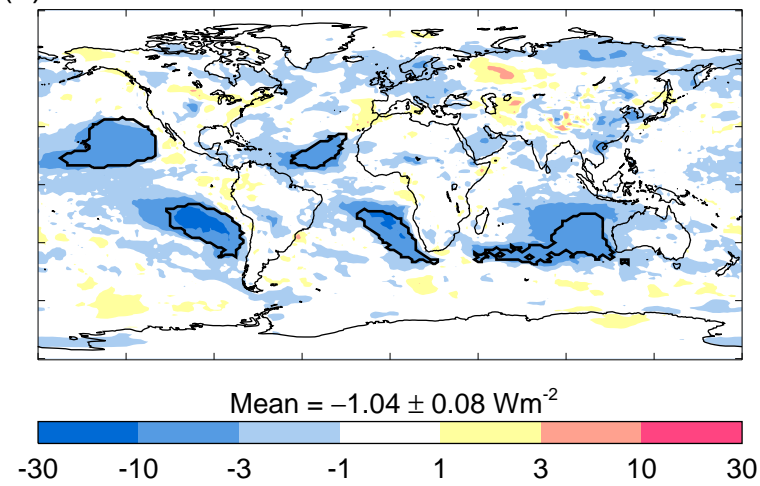

(b)

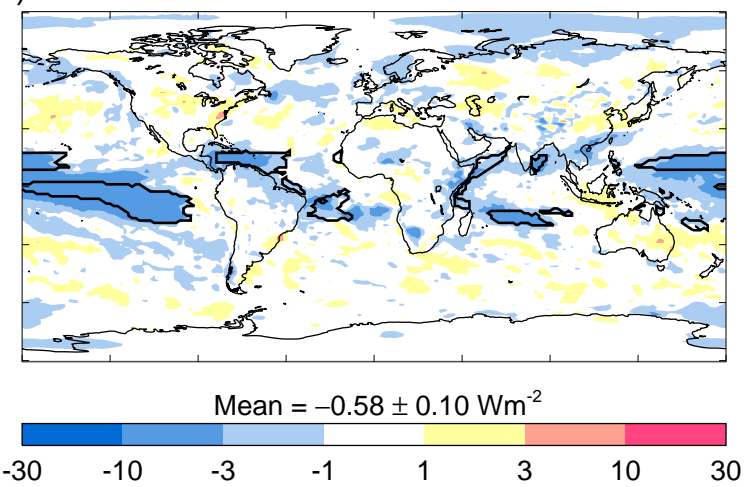

(c)

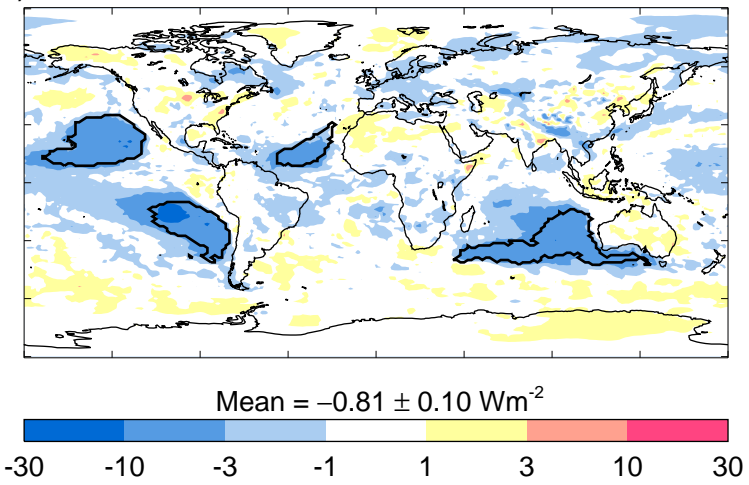

Fig. 3. RFPs due to geoengineered sea-spray aerosols using the different emission patterns, indicated by the thick black lines, with the 10 -year mean \pm one standard deviation. (a) I-mask; (b) D-mask; (c) I-mask NSA. $_{\text {. }}$.

of 2040-2069) with respect to present-day (mean of 19902019; years 1990-2005 are from the CMIP5 Historical simulation, years 2006-2019 from RCP4.5). All three emission patterns produce decreases in global mean precipitation from the levels in RCP4.5, equivalent to a $-1.3 \%$ reduction for Imask, $-0.4 \%$ for D-mask and $-1.2 \%$ for I-mask $\mathrm{NSA}_{\mathrm{NA}}$. These reductions to some degree counteract the $2.5 \%$ increase in global-mean precipitation in RCP4.5 compared with present- (a)
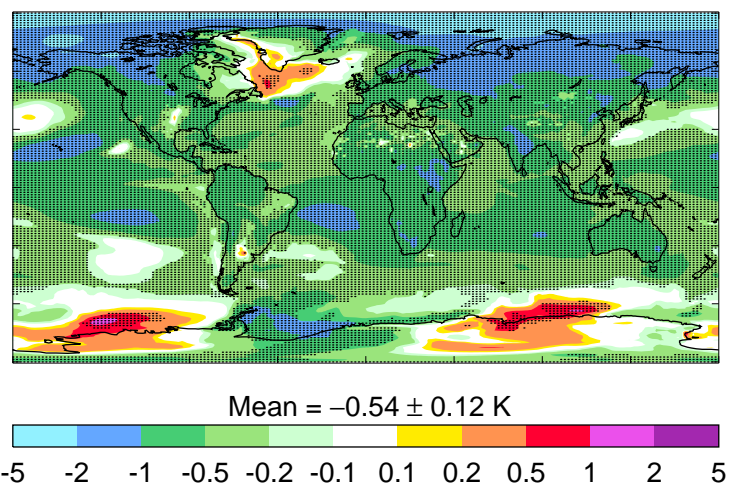

(b)
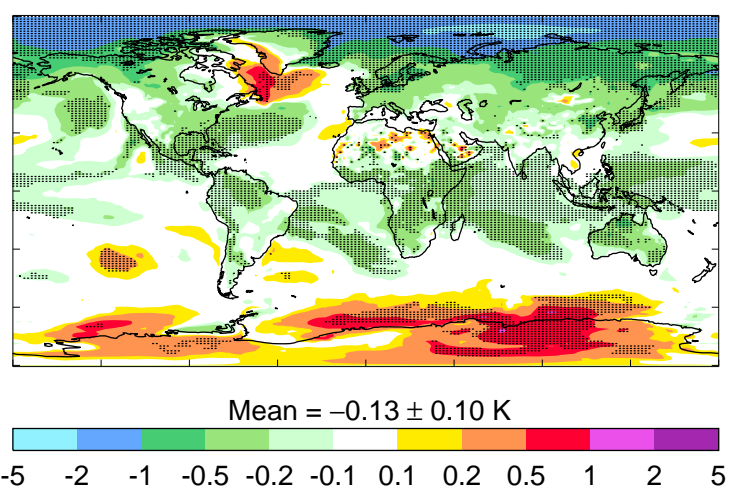

(c)

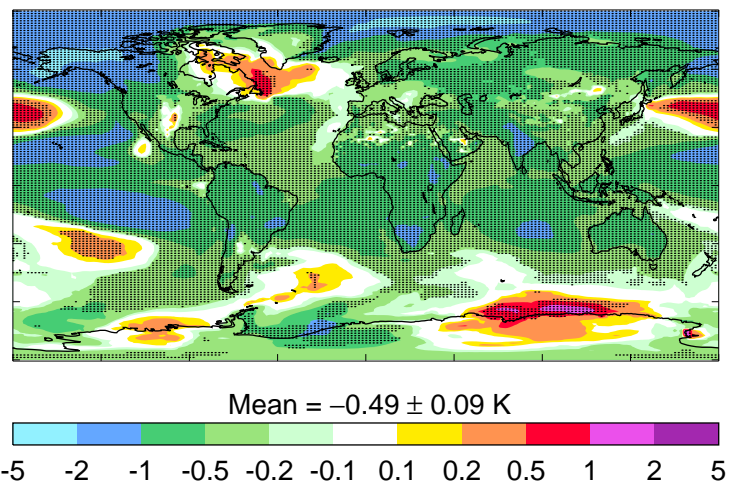

Fig. 4. (a) Mean 2040-2069 change in near-surface air temperature $(\mathrm{K})$ with respect to RCP4.5 when using the I-mask pattern for emitting geoengineered sea-spray. (b) As (a) but using the D-mask

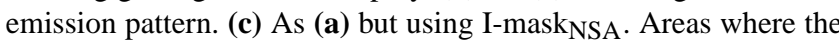
changes are significant at the $5 \%$ level are shaded.

day. The greatest changes are in the tropics and sub-tropics, associated with perturbations to the position of the intertropical convergence zone (ITCZ), leading to both increases and decreases in regional precipitation. The I-mask and Imask $_{\text {NSA }}$ simulations, which had the largest reductions in surface temperature, also show the largest changes in precipitation; the D-mask simulation, in which there was only a small cooling, has much smaller changes. 


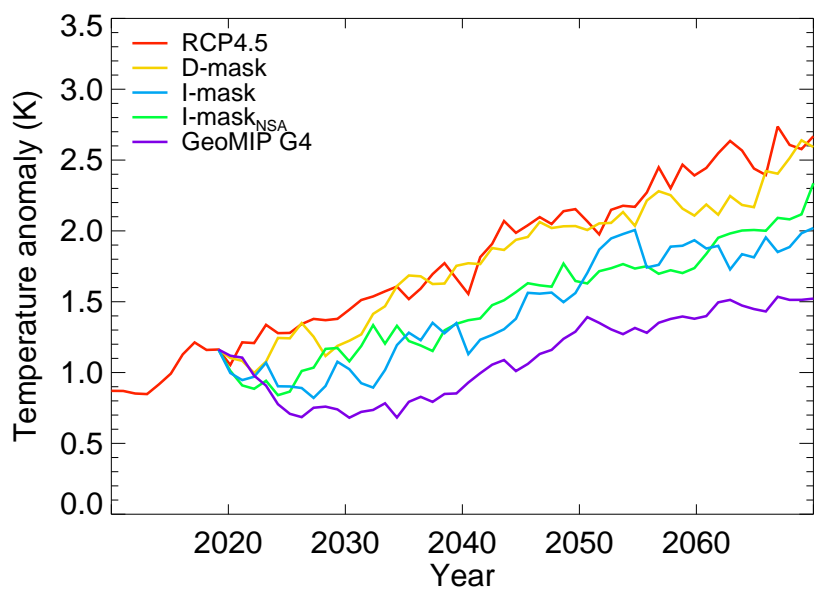

Fig. 5. Evolution of global-mean near-surface temperature anomaly (K) with respect to the pre-industrial mean.

Over land, the I-mask simulation generally shows increases north of the equator in the far north of South America, central Africa and India, with decreases to the south of the equator especially in the west of the Amazon basin and the Nordeste region of Brazil. There are also indications of a precipitation reduction in the southern USA. The Dmask simulation has only small changes in precipitation over land, mainly in South America. In I-mask $\mathrm{NSA}_{\mathrm{N}}$ the changes are generally distributed in a similar pattern to I-mask over land but to a different degree. The precipitation increases are larger over India but smaller over central Africa, there is a greater reduction in precipitation in the southern USA, and an area of statistically significant reduction in Europe. A rather different pattern is seen in South America, which although still showing precipitation reduction in the western Amazon basin, also has a much larger area of increase in the north and northeast of South America, with decreases on the Atlantic coast south of $30^{\circ} \mathrm{S}$. There are no significant precipitation changes in the Nordeste region in this simulation.

Given the different precipitation responses when using the three different emission patterns, it is obvious that geoengineering does not simply reverse the precipitation changes induced by climate change. In some regions (e.g. the south-east

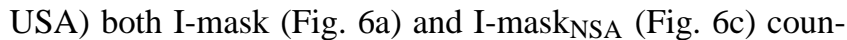
teract the increased precipitation seen in RCP4.5 (Fig. 6d). However, the same simulations both show an increase in precipitation over India, an area where precipitation is already increased in RCP4.5.

\subsection{Soil moisture}

Changes in soil moisture content, shown in Fig. 7, affect vegetation more directly than changes in precipitation and are often distributed in a similar manner. For I-mask (Fig.7a) there are notable areas of drying in South America and the southern USA, with increases in soil moisture in central Africa and India. Not all changes in soil moisture closely follow changes in precipitation: the increases in high northern latitudes are related to an increased fraction of frozen (and hence immobile) soil moisture in the cooler geoengineered climate. As with temperature and precipitation, the changes with Dmask are much smaller. The changes in the I-mask NSA $_{\text {sim- }}$ ulation are again similar to those in precipitation, with the sizable area of drying in northern and eastern Europe being a notable feature.

\subsection{Net primary productivity}

The impact of geoengineering on the net primary productivity of vegetation (NPP, Fig. 8) will be a combination of, at the least, its impact on temperature and soil moisture. Other factors can also be important, such as any impact on the ratio of diffuse to direct solar radiation at the surface, e.g. Mercado et al. (2009). Some changes in NPP follow those in soil moisture and precipitation: in the I-mask simulation (Fig. 8a) there are NPP reductions in the southern USA and eastern coastal regions of South America, and significant areas of increase, such as central Africa and northern India. Other regions, such as the western Amazon basin, show a drying of soil moisture, but the geoengineered cooling of this high temperature region more than compensates for this, giving an increase in NPP. The opposite effect tends to occur at high northern latitudes, where the geoengineered cooling reduces

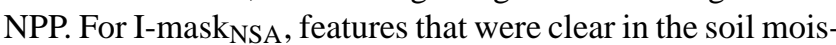
ture changes are also present in NPP, such as the larger reduction in the southern USA and Europe, and the increase in parts of northern South America. NPP changes in the D-mask simulation are again much smaller.

\section{Discussion and conclusions}

The simulations used to calculate radiative forcing and RFP indicated that the direct effect of geoengineered sea-spray is not insignificant when compared with its impact on clouds, in agreement with Partanen et al. (2012). Consequently, it was thought useful to assess the impact of sea-spray geoengineering if two emission strategies were followed, one taking the effect on clouds to be most important, the other considering the effect in clear skies as primary. Because such aerosols in the real world will always have both effects depending on their environment, we did not force the sea-spray aerosols in the coupled-model simulations to have only direct or indirect effects. Instead we allowed all aerosol effects to operate and modelled the two different emission strategies by targeting emissions in different areas of the ocean.

The efficiency per unit RFP of the different emission patterns in changing global-mean temperature and precipitation are given in Table 2 . The efficiency of cooling when using the D-mask emission pattern for sea-spray geoengineering is less than half that obtained when using the other emission 
(a)
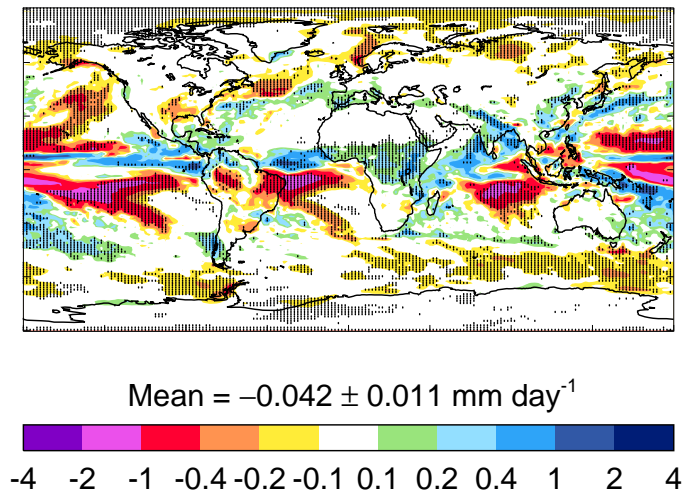

(c)
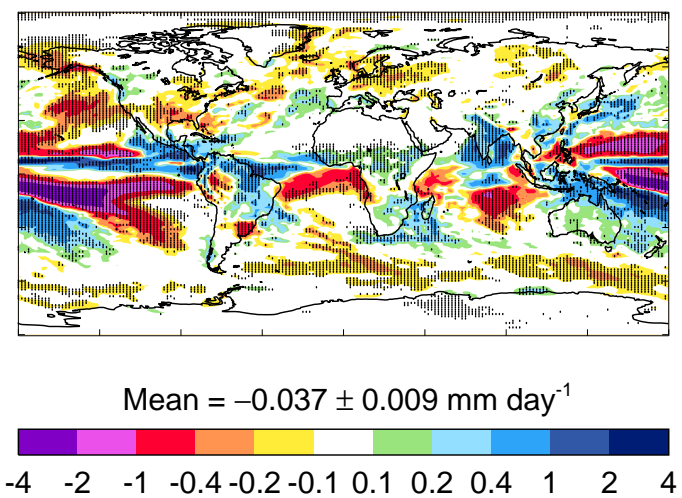

(b)
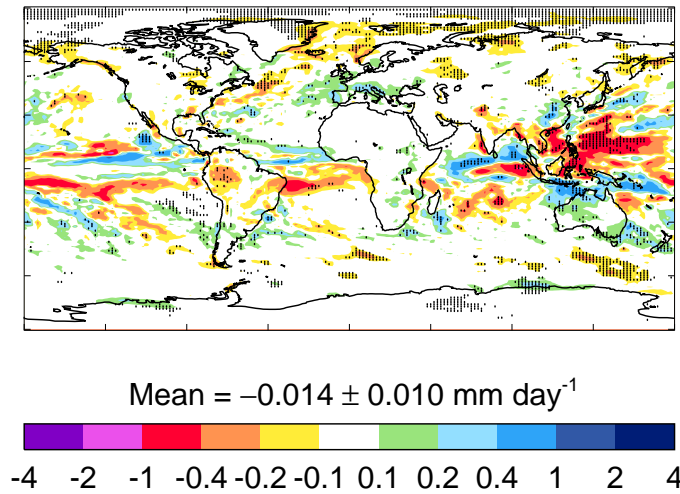

(d)
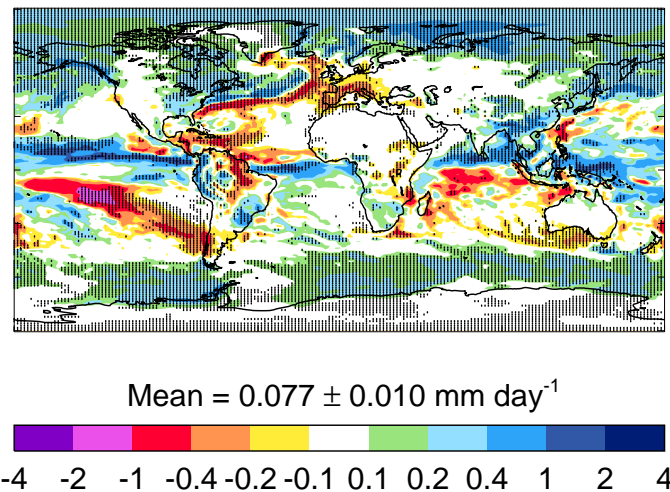

Fig. 6. (a) Mean 2040-2069 change in precipitation rate $\left(\mathrm{mm} \mathrm{day}^{-1}\right)$ with respect to the same period in RCP4.5 when using the I-mask

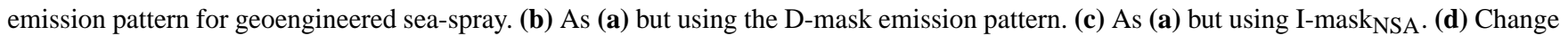
in precipitation rate in RCP4.5 between 1990-2019 and 2040-2069. Areas where changes are significant at the 5\% level are shaded.

patterns, despite having a burden of geoengineered aerosol about a third higher, consistent with its increased lifetime. This appears to be related to a feedback via clouds. In the atmosphere-only simulations with fixed sea-surface temperatures used to determine the RFP, emitting sea-spray aerosols using the D-mask emission pattern caused little change in net cloud forcing $\left(+0.04 \mathrm{Wm}^{-2}\right.$ in the global mean, only $2.5 \times 10^{-4} \mathrm{Wm}^{-2}$ for the region between $30^{\circ} \mathrm{N} / \mathrm{S}$ ). However, in the fully-coupled simulations with D-mask, net cloud forcing is changed much more, especially in the tropics $\left(+0.16 \mathrm{Wm}^{-2}\right.$ in the global mean, $+0.32 \mathrm{Wm}^{-2}$ between $30^{\circ} \mathrm{N} / \mathrm{S}$ ). The reduction in cloud forcing is due to a thinning or reduction in cloud in the fully-coupled simulations, as the change in clear-sky fluxes due to geoengineered sea-salt was very similar in the fully-coupled and atmosphere-only simulations. As this cloud reduction only occurs in the simulations with interactive sea-surface temperatures, this may be a consequence of the geoengineered sea-salt reducing the flux of solar radiation to the surface and so reducing convection. The reduction in the cooling effect of cloud will con- tribute to the reduced impact of geoengineering on surface temperature in the D-mask case. When comparing changes in global mean precipitation, although the reduction in D-mask is much smaller in absolute terms than I-mask or I-mask NSA (Table 2), per unit global cooling it in fact produces $\sim 50 \%$ greater reduction in precipitation. These results suggest that, although it is important to consider the direct radiative effect of geoengineered sea-spray aerosols, their impact on clouds is more important. Also included in Table 2 is the cooling efficiency per unit emission of geoengineered sea-salt, which ranges from $-0.7 \times 10^{-4}$ to $-3.3 \times 10^{-4} \mathrm{~K}$ per kg s${ }^{-1}$. Therefore in order to cool the planet by $1 \mathrm{~K}$, our model suggests that between $\sim 3-14$ tonnes of sea-salt would need to be injected into the atmosphere every second, depending on the emission areas chosen.

One of the main results from a previous study (Jones et al., 2009) was the negative impact on precipitation over parts of South America, a result also obtained by Latham et al. (2012). In Jones et al. (2009) this reduction was linked to geoengineering in the South Atlantic stratocumulus area and 
(a)
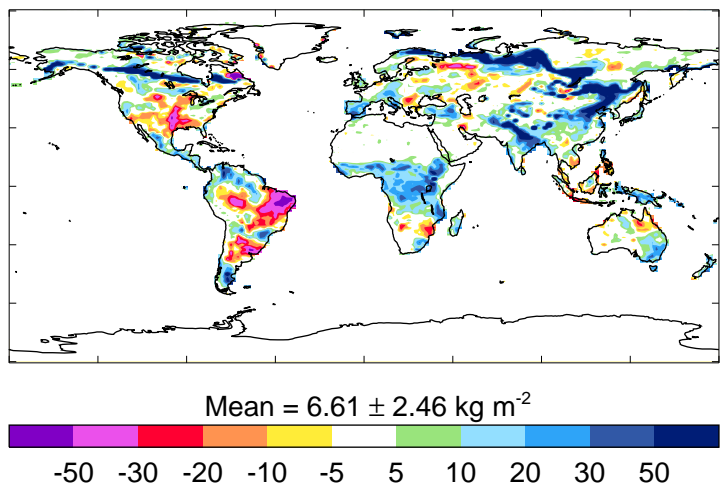

(b)

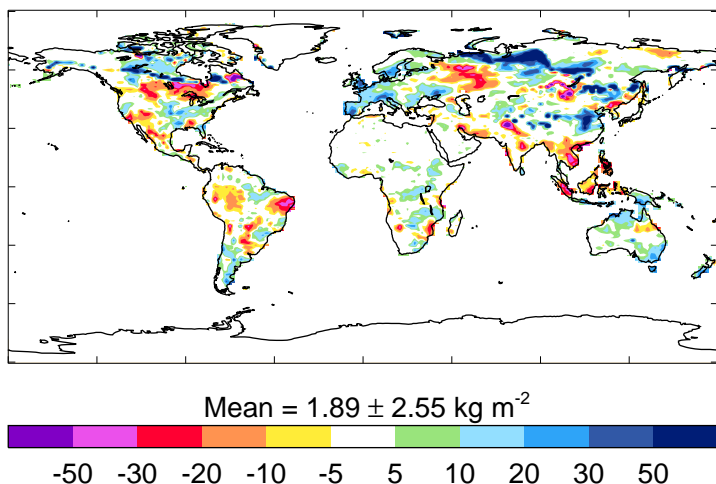

(c)

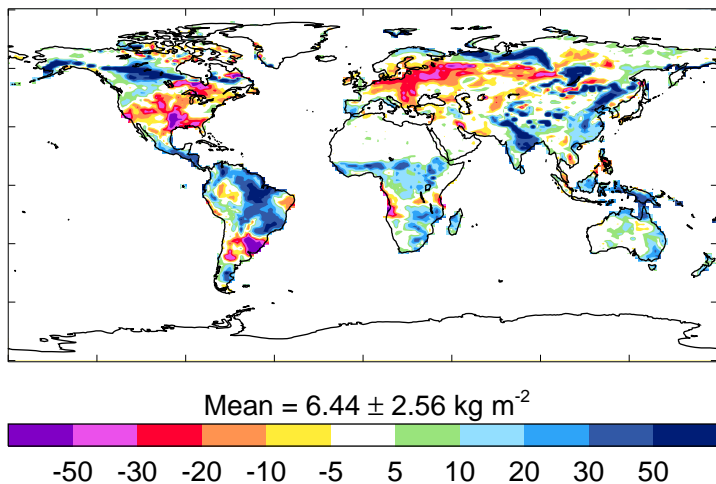

Fig. 7. (a) Mean 2040-2069 change in soil moisture content (kg $\mathrm{m}^{-2}$ ) with respect to RCP4.5 when using the I-mask distribution for emitting geoengineered sea-spray. (b) As (a) but using the Dmask emission pattern. (c) As (a) but using I-mask $\mathrm{NSA}_{\text {. }}$

is the reason for defining the I-mask $\mathrm{NSA}_{\mathrm{N}}$ emission pattern which excludes this area. Fig. 9 shows a comparison of the the percentage change in 30-year mean precipitation over the central and southern Pacific/Atlantic regions from the results of Jones et al. (2009) (Fig. 9a) compared with those from I-mask and I-mask ${ }_{\text {NSA }}$ (Fig. 9b and c, respectively). The patterns of change are broadly similar in Fig. 9a and 9b, supporting the result of Jones et al. (2009). There is obviously less impact over the north of South America in I-mask com- (a)

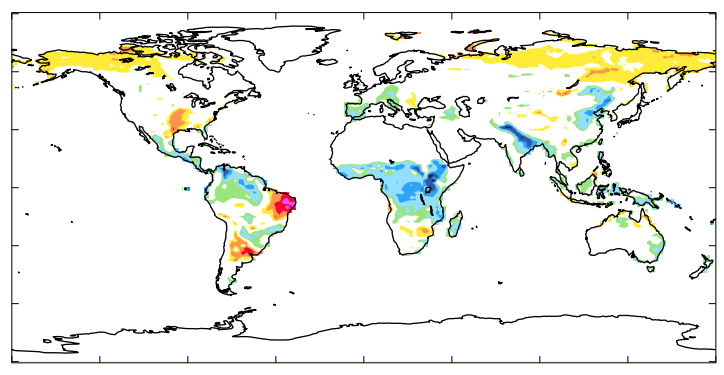

Mean $=0.016 \pm 0.014 \mathrm{~kg}[\mathrm{C}] \mathrm{m}^{-2} \mathrm{yr}^{-1}$

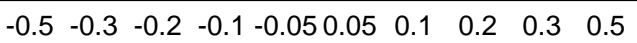

(b)

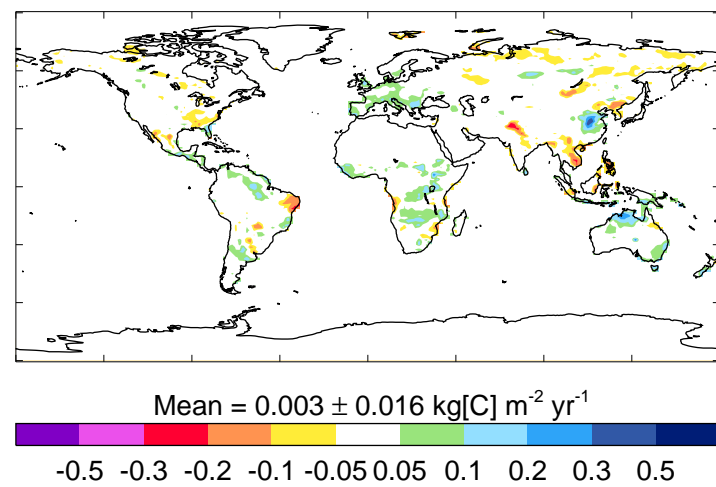

(c)

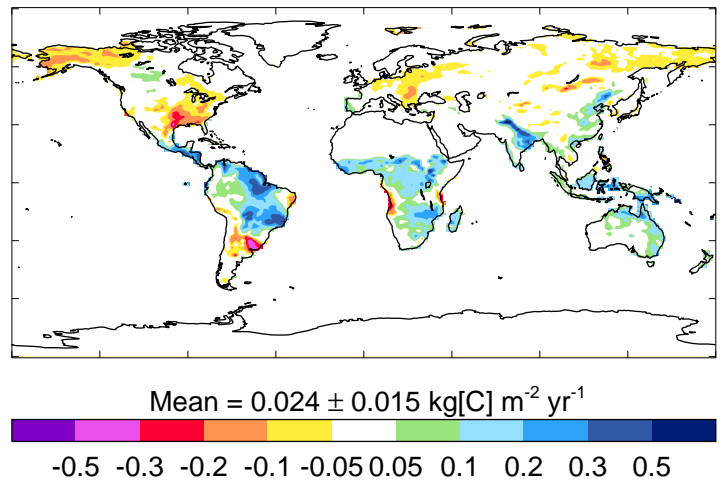

Fig. 8. As Fig. 7 but for mean 2040-2069 changes in vegetation net primary productivity $\left(\mathrm{kg}[\mathrm{C}] \mathrm{m}^{-2} \mathrm{yr}^{-1}\right)$. (a) I-mask; (b) D-mask; (c) I-mask $\mathrm{NSA}_{\text {. }}$.

pared with the results of Jones et al. (2009), which might be expected given the different manner the geoengineering was simulated in each case. The global mean RFP in both cases is very similar, but in Jones et al. (2009) the local RFP is large and concentrated in small regions (see Fig. 10), whereas in the present study it is more diffuse, with smaller values over a larger area (Fig. 3a). Consequently, the RFP in I-mask is not as inhomogeneous as in Jones et al. (2009) and so the regional impact is reduced (Jones et al., 2011). 


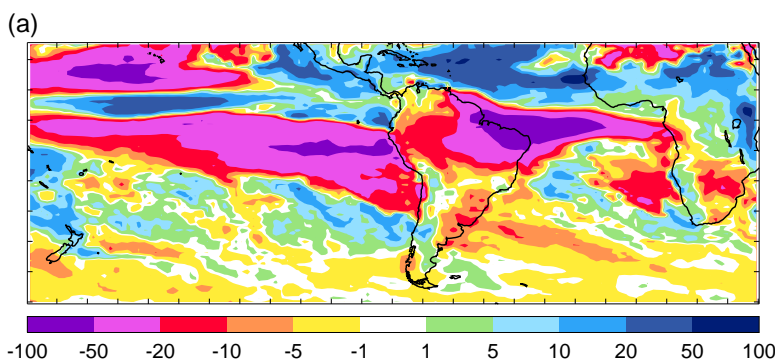

(b)

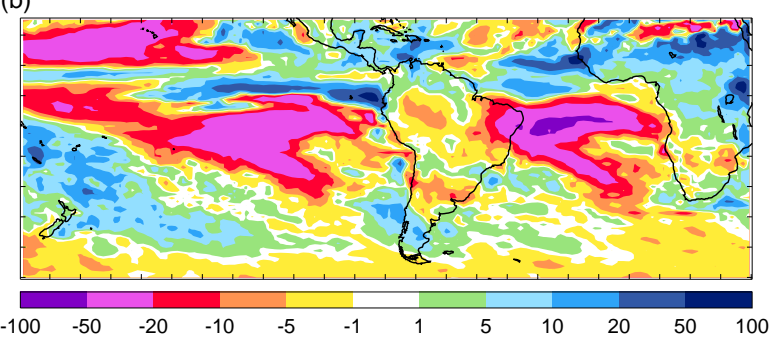

(c)

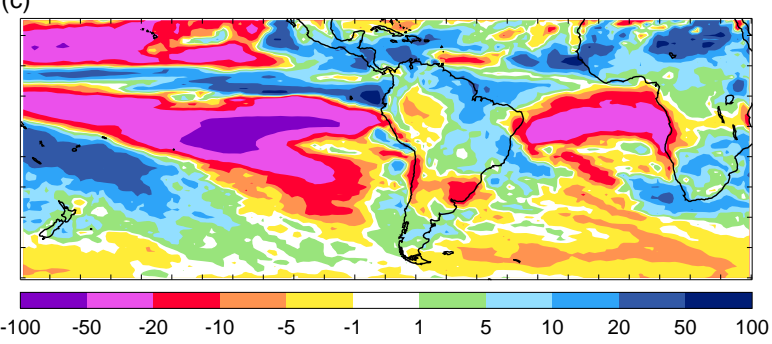

Fig. 9. (a) Percentage change in precipitation from the "ALL" case of Jones et al. (2009). (b) As (a) but for I-mask. (c) As (a) but for I-mask $\mathrm{NSA}_{\text {. }}$

If geoengineered sea-spray emissions in the South Atlantic

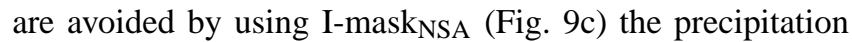
changes over the ocean and the southern part of South America are similar to those in I-mask, as are the changes in the western Amazon basin. However, the more central and eastern areas of Amazonia now show an increase in rainfall, although there is still a large area of precipitation reduction just offshore which affects the far east of the Nordeste region. Although there are differences in precipitation changes between I-mask and I-mask $\mathrm{NSA}_{\mathrm{A}}$, the northward movement of the precipitation maximum associated with the ITCZ in the Atlantic is still evident. Any process which affects the position of the ITCZ and the large amount of precipitation associated with it will have an impact on adjacent ecosystems and their populations. These impacts could be positive as well as negative: for example, while precipitation and NPP decrease in the Nordeste region, they increase in sub-Saharan Africa in all three simulations shown in Fig. 9. Additionally, while we have concentrated on precipitation changes over large landmasses, the impact of any changes in seasonal rainfall patterns on small island communities should not be forgotten.
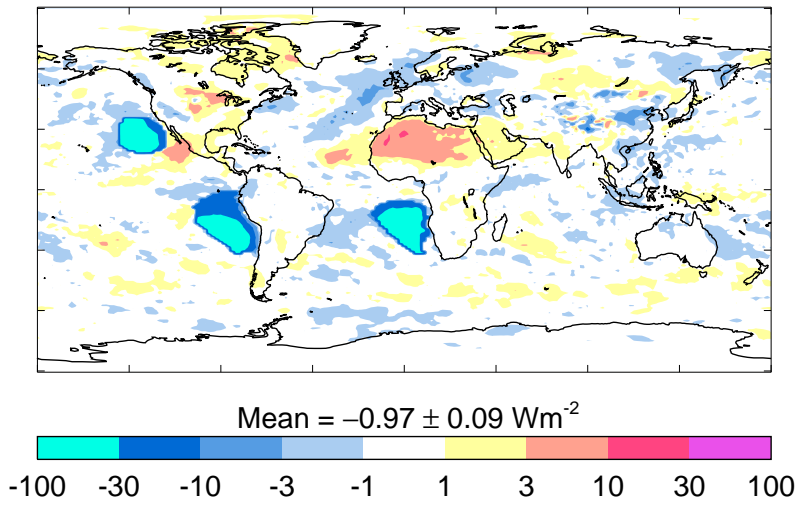

Fig. 10. $\mathrm{RFP}\left(\mathrm{Wm}^{-2}\right)$ due to modified marine stratocumulus clouds from Jones et al. (2009) $\left(\mathrm{Wm}^{-2}\right)$.

It is also interesting to compare the mean results from the three experiments using sea-spray geoengineering with those from the GeoMIP G4 experiment which injects $\mathrm{SO}_{2}$ into the lower stratosphere (Table 2). The RFP in G4 is greater than produced by sea-spray geoengineering but of a similar order of magnitude. G4 shows the greatest efficiency in reducing global-mean temperature per unit RFP and has the lowest impact on global-mean precipitation per unit cooling.

Conclusions from any modelling study can only be as reliable as the model's treatment of physical processes. Some studies, e.g. Quaas et al. (2006), suggest that models tend to overestimate the radiative impact of aerosol indirect effects when compared with satellite measurements. On the other hand, other studies, such as Penner et al. (2011), suggest that satellite-based methods underestimate indirect forcing by aerosols. The processes surrounding aerosol-cloud interactions are highly complex and uncertain, so a degree of caution is required when assessing the results of simulations where such interactions are central. Bearing these caveats in mind, the main conclusions from this study are:

1. The direct radiative effect of geoengineered sea-spray aerosol in clear skies is significant and should be taken into account, but its indirect effects on clouds are of greater importance in our model.

2. Consequently, targeting sea-spray emissions to maximise indirect effects appears a better strategy for reducing global mean temperature while minimising precipitation changes than using emission patterns which maximise the direct effect. This conclusion could be altered by choosing different emission regions, fluxes or size parameters, but holds for those studied here.

3. The more detailed treatment of sea-spray aerosols shows impacts on climate (specifically precipitation) which are similar in character, though reduced in degree, to those obtained previously using a much simpler treatment. 
Such conclusions may of course be model dependent, which emphasises the importance of initiatives such as GeoMIP in attempting a more general consensus.

Acknowledgements. We would like to thank Johannes Quaas for help with the satellite retrieval data. This work was supported by the Joint DECC/Defra Met Office Hadley Centre Climate Programme (GA01101) and by a joint EPSRC/NERC initiative via the Integrated Assessment of Geoengineering Proposals (IAGP; http://www.iagp.ac.uk/), contract number EPSRC EP/I014721/1. This work is distributed under the Creative Commons Attribution 3.0 License together with an author copyright. This license does not conflict with the regulations of Crown Copyright.

Edited by: H. Tost

\section{References}

Alterskjær, K., Kristjánsson, J. E., and Seland, Ø.: Sensitivity to deliberate sea salt seeding of marine clouds - observations and model simulations, Atmos. Chem. Phys., 12, 2795-2807, doi:10.5194/acp-12-2795-2012, 2012.

Bellouin, N., Rae, J., Jones, A., Johnson, C., Haywood, J., and Boucher, O.: Aerosol forcing in the Climate Model Intercomparison Project (CMIP5) simulations by HadGEM2-ES and the role of ammonium nitrate, J. Geophys. Res., 116, D20206, doi:10.1029/2011JD016074, 2011.

Collins, W. J., Bellouin, N., Doutriaux-Boucher, M., Gedney, N., Halloran, P. Hinton, T., Hughes, J., Jones, C. D., Joshi, M., Liddicoat, S., Martin, G., O'Connor, F., Rae, J., Senior, C., Sitch, S., Totterdell, I., Wiltshire, A., and Woodward, S.: Development and evaluation of an Earth-system model - HadGEM2, Geosci. Model Dev., 4, 1051-1075, doi:10.5194/gmd-4-10512011, 2011.

Crutzen, P.: Albedo enhancement by stratospheric sulfur injections: A contribution to resolve a policy dilemma?, Clim. Change, 77, 211-220, doi:10.1007/s10584-006-9101-y, 2006.

Haywood, J., Donner, L., Jones, A., and Golaz, J.-C.: Global indirect radiative forcing caused by aerosols: IPCC (2007) and beyond, in: Clouds in the Perturbed Climate System: Their Relationship to Energy Balance, Atmospheric Dynamics, and Precipitation, Strüngmann Forum Report, edited by Heintzenberg, J., and Charlson, R. J., MIT Press, Cambridge, USA, 451-467, 2009.

Jones, A., Roberts, D. L., Woodage, M. J., and Johnson, C. E.: Indirect sulphate aerosol forcing in a climate model with an interactive sulphur cycle, J. Geophys. Res., 106, 20293-20310, doi:10.1029/2000JD000089, 2001.

Jones, A., Haywood, J., and Boucher, O.: Climate impacts of geoengineering marine stratocumulus clouds, J. Geophys. Res., 114, D10106, doi:10.1029/2008JD011450, 2009.

Jones, A., Haywood, J., and Boucher, O.: A comparison of the climate impacts of geoengineering by stratospheric $\mathrm{SO}_{2}$ injection and by brightening of marine stratocumulus cloud, Atmos. Sci. Lett., 12, 176-183, doi:10.1002/as1.291, 2011.

Korhonen, H., Carslaw, K. S., and Romakkaniemi, S.: Enhancement of marine cloud albedo via controlled sea spray injections: a global model study of the influence of emission rates, microphysics and transport, Atmos. Chem. Phys., 10, 4133-4143, doi:10.5194/acp-10-4133-2010, 2010.

Kravitz, B., Robock, A., Boucher, O., Schmidt, H., Taylor, K., Stenchikov, G., and Schulz, M.: The Geoengineering Model Intercomparison Project (GeoMIP), Atmos. Sci. Lett., 12, 162167, doi:10.1002/asl.316, 2011.

Landrum, L., Holland, M. K., and Schneider, D. P.: Antarctic sea ice climatology, variability, and late twentieth-century change in CCSM4, J. Clim., 25, 4817-4838, doi:10.1175/JCLI-D-1100289.1, 2012.

Latham, J.: Control of global warming? Nature, 347, 339-340, doi:10.1038/347339b0, 1990.

Latham, J.: Amelioration of global warming by controlled enhancement of the albedo and longevity of low-level maritime clouds, Atmos. Sci. Lett., 3, 52-58, doi:10.1006/Asle.2002.0048, 2002.

Latham, J., Rasch, P., Chen, C.-C., Kettles, L., Gadian, A., Gettelman, A., Morrison, H., Bower, K., and Choularton, T.: Global temperature stabilization via controlled albedo enhancement of low-level maritime clouds, Phil. Trans. R. Soc. A, 366, 39693987, doi:10.1098/rsta.2008.0137, 2008.

Latham, J., Bower, K., Choularton, T., Coe, H., Connoly, P., Cooper, G., Craft, T., Foster, J., Gadian, A., Galbraith, L., Iacovides, H., Johnston, D., Launder, B., Leslie, B., Meyer, J., Neukermans, A., Ormond, B., Parkes, B., Rasch, P., Rush, J., Salter, S., Stevenson, T., Wang, H., Wang, Q., and Wood, R.: Marine cloud brightening, Phil. Trans. R. Soc. A, 370, 4217-4262, doi:10.1098/rsta.2012.0086, 2012.

Lenton, T. M., and Vaughan, N. E.: The radiative forcing potential of different climate geoengineering options, Atmos. Chem. Phys., 9, 5539-5561, doi:10.5194/acp-9-5539-2009, 2009.

Lohmann, U., Rotstayn, L., Storelvmo, T., Jones, A., Menon, S., Quaas, J., Ekman, A. M. L., Koch, D., and Ruedy, R.: Total aerosol effect: radiative forcing or radiative flux perturbation? Atmos. Chem. Phys., 10, 3235-3246, doi:10.5194/acp-10-32352010, 2010.

Martin, G. M., Bellouin, N., Collins, W. J., Culverwell, I. D., Halloran, P. Hardiman, S., Hinton, T. J., Jones, C. D., McLaren, A., O'Connor, F., Rodriguez, J., Woodward, S., Best, M., Brooks, M. E., Brown, A. R., Butchart, N., Dearden, C., Derbyshire, S. H., Dharssi, I., Doutriaux-Boucher, M., Edwards, J. M., Falloon, P., Gedney, N., Gray, L., Hobson, M., Huddleston, M., Hughes, J., Ineson, S., Ingram, W., James, P. M., Johns, T. C., Johnson, C., Jones, A., Jones, C. P., Joshi, M., Liddicoat, S., Lock, A. P., Maidens, A., Milton, S. F., Rae, J., Sellar, A., Senior, C. A., Totterdell, I., Verhoef, A., Vidale, P. L., and Wiltshire, A.: The HadGEM2 family of Met Office Unified Model climate configurations, Geosci. Model Devel., 4, 723757, doi:10.5194/gmd-4-723-2011, 2011.

Mercado, L., Bellouin, N., Boucher, O., Sitch, S., Huntingford, C., Wild, M., and Cox, P.: Impact of changes in diffuse radiation on the global land carbon sink, Nature, 458, 1014-1017, doi:10.1038/nature07949, 2009.

Minnis, P., Sun-Mack, D. F., Heck. P. W., Doelling, D. R., and Trepte, Q. Z.: CERES cloud property retrievals from imagers on TRMM, Terra, and Aqua, Proc. SPIE 10th International Symposium on Remote Sensing: Conference on Remote Sensing of Clouds and the Atmosphere VII, Barcelona, Spain, September 8-12, 5235, 37-48, 2003. 
Moss, R. H., Edmonds, J. A., Hibbard, K. A., Manning, M. R., Rose, S. K., van Vuuren, D. P., Carter, T. R., Emori, S., Kainuma, M., Kram, T., Meehl, G. A., Mitchell, J. F. B., Nakicenovic, N., Riahi, K., Smith, S. J., Stouffer, R. J., Thomson, A. M., Weyant, J. P., and Wilbanks, T. J.: The next generation of scenarios for climate change research and assessment, Nature, 463, 747-756, doi:10.1038/nature08823, 2010.

Partanen, A.-I., Kokkola, H., Romakkaniemi, S., Kerminen, V.-M., Lehtinen, K. E. J., Bergman, T., Arola, A., and Korhonen, H.: Direct and indirect effects of sea spray geoengineering and the role of injected particle size, J. Geophys. Res., 117, D02203, doi:10.1029/2011JD016428, 2012.

Penner, J. E., Xu, L., and Wang, M.: Satellite methods underestimate indirect climate forcing by aerosols, Proc. Nat. Acad. Sci. U.S.A., 108, 13404-13408, doi:10.1073/pnas.1018526108, 2011.

Platnick, S., King, M. D., Ackerman, S. A., Menzel, W. P., Baum, B. A., Riédi, J. C., and Frey, R. A.: The MODIS cloud products: Algorithms and examples from Terra, IEEE Trans. Geosci. Rem. Sens., 41, 459-473, 2003.

Quaas, J., Boucher, O., and Lohmann, U.: Constraining the total aerosol indirect effect in the LMDZ and ECHAM4 GCMs using MODIS satellite data, Atmos. Chem. Phys., 6, 947-955, doi:10.5194/acp-6-947-2006, 2006.
Quaas, J., Ming, Y., Menon, S., Takemura, T., Wang, M., Penner, J. E., Gettelman, A., Lohmann, U., Bellouin, N., Boucher, O., Sayer, A. M., Thomas, G. E., McComiskey, A., Feingold, G., Hoose, C., Kristjánsson, J. E., Liu, X., Balkanski, Y., Donner, L. J., Ginoux, P. A., Stier, P., Grandey, B., Feichter, J., Sednev, I., Bauer, S. E., Koch, D., Grainger, R. G., Kirkevåg, A., Iversen, T., Seland, Ø., Easter, R., Ghan, S. J., Rasch, P. J., Morrison, H., Lamarque, J.-F., Iacono, M. J., Kinne, S., and Schulz, M.: Aerosol indirect effects - general circulation model intercomparison and evaluation with satellite data, Atmos. Chem. Phys., 9, 8697-8717, 2009, http://www.atmos-chem-phys.net/9/8697/2009/.

Rasch, P. J., Latham, J., and Chen, C.-C.: Geoengineering by cloud seeding: influence on sea ice and climate system, Environ. Res. Lett., 4, 045112, doi:10.1088/1748-9326/4/4/045112, 2009.

Robock, A.: 20 reasons why geoengineering may be a bad idea, Bull. Atomic Scientists, 64, 14-18, 59, doi:10.2968/064002006, 2008.

Salter, S., Sortino, G., and Latham, J.: Sea-going hardware for the cloud albedo method of reversing global warming, Phil. Trans. R. Soc. A, 366, 3989-4006, doi:10.1098/rsta.2008.0136, 2008.

Taylor, K. E., Stouffer, R. J., and Meehl, G. A.: A summary of the CMIP5 experimental design, Report of the World Climate Research Program, Geneva, Switzerland, available at: http: //cmip-pcmdi.llnl.gov/cmip5/experiment_design.html, 2009. 